\title{
Pulse source injection molecular beam epitaxy and characterization of nano-scale thin GaN layers on Si substrates
}

\author{
W. Tong ${ }^{\text {a }}$, M. Harris ${ }^{\text {a }}$, B.K. Wagner ${ }^{\text {a }}$, J.W. Yu ${ }^{\text {b }}$, H.C. Lin ${ }^{\text {b }}$, Z.C. Feng ${ }^{\text {b** }}$ \\ ${ }^{a}$ Georgia Tech Research Institute, Georgia Institute of Technology, Atlanta, GA 30332, USA \\ ${ }^{\mathrm{b}}$ Graduate Institute of Electro-Optical Engineering and Department of Electrical Engineering, National Taiwan University, Taipei 106-17, Taiwan, ROC
}

Available online 29 August 2005

\begin{abstract}
We report the successful growth of thin GaN layers on (111) orientated Si substrates utilizing a newly developed pulse source injection molecular beam epitaxial (PSIMBE) technique. RHEED patterns showed that two-dimensional layer-by-layer growth started at a very early stage during deposition (within $20 \mathrm{~nm}$ ). AFM studies showed that an almost atomically smooth surface was obtained with an area RMS roughness of less than $0.2 \mathrm{~nm}$. The crystal structure and quality were determined from high resolution 2-Theta-Omega scan and exhibited only three strong and sharp lines at $28.56^{\circ}, 34.70^{\circ}$ and $73.05^{\circ}$ due to the Si substrate and the single crystalline wurtzite (w-) GaN (0002) and (0004), respectively. Raman scattering study showed the characteristic w-GaN $\mathrm{E}_{2}$ band at 565 wave-numbers and the longitudinal optical (LO) phonon-plasma coupling mode at $731 \mathrm{~cm}^{-1}$. These data indicate the success of MBE growth of single crystalline w-GaN thin layers on the order of less than 100-nm thick on Si substrates without using a complicated buffer structure.
\end{abstract}

(C) 2005 Elsevier B.V. All rights reserved.

Keywords: GaN; Si; PSIMBE; Optical reflectance; X-ray diffraction; Raman scattering; Photoluminescence; Reflection high-energy electron diffraction; Atomic force microscopy

\section{Introduction}

GaN-based materials and structures have attracted much interest in recent years for applications such as UV-bluegreen light emitting diodes (LEDs), laser diodes (LDs) and other optoelectronic and electronic devices [1,2]. Despite recent breakthroughs in $\mathrm{GaN}$ device quality, developing a successful technique to grow high quality $\mathrm{GaN}$ on silicon for low cost production remains a great challenge. The favorable physical properties, high quality, and low cost of silicon make it a very attractive substrate for GaN-based devices especially for large-scale production. The crystal perfection of silicon is much higher than $\mathrm{SiC}$ and can be obtained with extremely smooth surfaces that satisfy the demanding morphology requirements for subsequent twodimensional expitaxial growth needed for device applications. Additionally, the use of Si promises the development

\footnotetext{
* Corresponding author. Tel.: +88623366 3543; fax: +8862 23637467 .

E-mail address: zcfeng@ee.cc.ntu.edu.tw (Z.C. Feng).
}

of a new generation of 21 st century devices through the integration of Si- and III-N based materials and technologies on one substrate.

To date, however, the quality of GaN grown on silicon is inferior to that grown on silicon carbide mainly due to the large lattice mismatch and big thermal expansion coefficient difference between these two materials [3]. Buffer layers with composite structures between $\mathrm{GaN}$ and $\mathrm{Si}$ have been employed to improve the quality of the GaN films, but with limited success [4-10]. A unique molecular beam epitaxial (MBE) process using pulsed source injection was developed at the Georgia Tech Research Institute to grow a thin GaN buffer layer for subsequent GaN layer growth. This pulse source injection molecular beam epitaxial (PSIMBE) technique provided sufficient relaxation time for the growth species on the growth surface to relax and grow two-dimensionally, thereby effectively overcoming the common problem of 3D nucleation of $\mathrm{GaN}$ at the early growth stage when a foreign substrate, such as $\mathrm{Si}$, was used [11-14]. 

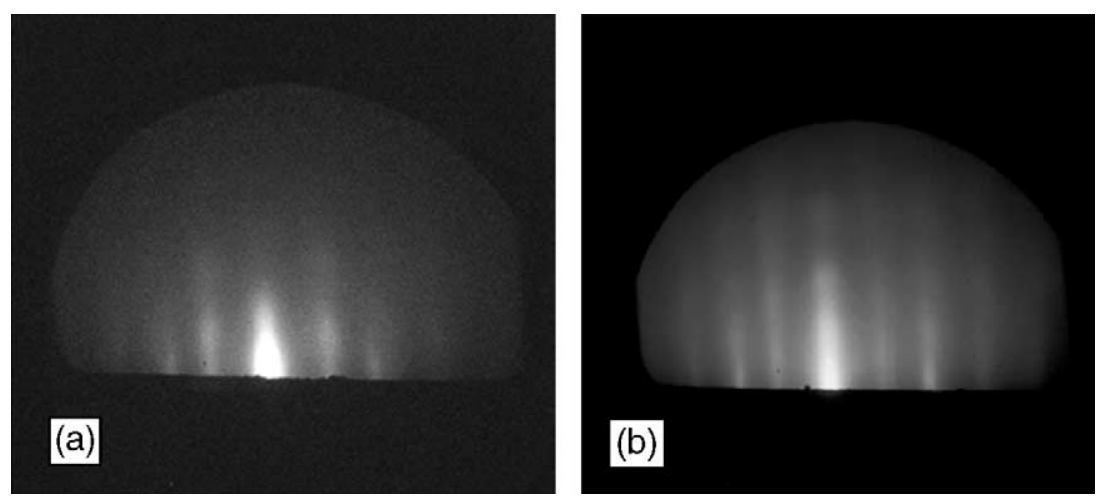

Fig. 1. RHEED pattern of AIN (a) and GaN/Si(111) (b) grown by PSIMBE.

In this study, we report the successful growth of thin GaN layers on (111) orientated Si substrates utilizing the PSIMBE process. These thin GaN layers can be used as an extremely smooth buffer layer for subsequent GaNbased device structure growth. The thin GaN layers were characterized by a variety of techniques such as reflection high-energy electron diffraction (RHEED), high resolution X-ray diffraction (HRXRD), optical reflectance (OR), atomic force microscopy (AFM), room temperature photoluminescence (PL) and Raman scattering (RS).

\section{Experiment}

A MBE system, equipped with an EPI UNI-Bulb RF Source and an EPI SUMO thermal effusion cell, was used for this research. The system was pumped by a Leybold magnetic bearing turbo pump and a cryopump. The nitrogen gas flow was controlled by a MKS 1479A gas flow controller and $\mathrm{Ga}$ was thermally evaporated from the SUMO cell. An EPI hot tip effusion cell was used to evaporate $\mathrm{Al}$ to grow an $\mathrm{AlN}$ buffer layer on silicon prior to $\mathrm{GaN}$ growth. The UNI-Bulb plasma source was operated at $350 \mathrm{~W}$ with a nitrogen flow rate of $0.6 \mathrm{sccm}$ for this study. The background pressure of the chamber during the deposition was $6.0 \times 10^{-6}$ Torr.

During the growth, silicon (111) substrates were first etched with buffered HF (6:1) solution for 2 min prior to loading into the system. The substrates were baked in the

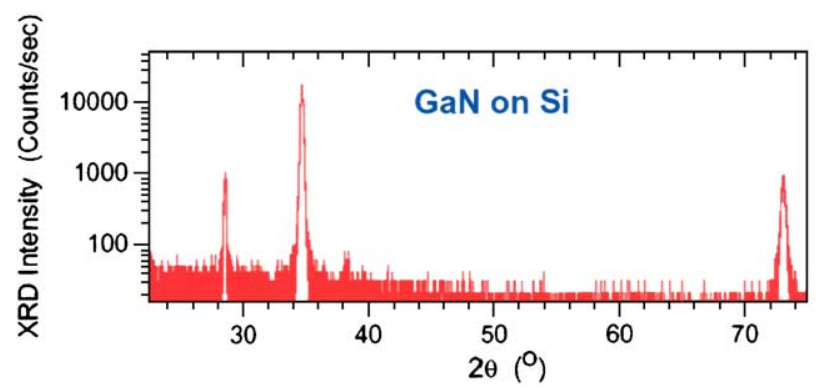

Fig. 2. High resolution XRD characterization of GaN/Si (111) grown with pulsed source injection MBE. chamber at $80{ }^{\circ} \mathrm{C}$ for $24 \mathrm{~h}$ before growth. The $\mathrm{Al}$ layer was first deposited on the silicon with a flux of $4 \times 10^{-8}$ Torr for $1 \mathrm{~min}$ and then the nitrogen plasma was introduced to form an AlN buffer layer for GaN growth. Growth temperatures for AlN were between $650{ }^{\circ} \mathrm{C}$ and $800{ }^{\circ} \mathrm{C}$ and the typical AlN buffer layer thickness was less than $10 \mathrm{~nm}$. Ga and $\mathrm{N}$ plasmas were alternatively injected onto the surface for GaN growth. The duration of injection of each source was varied from $1 \mathrm{~min}$ to $3 \mathrm{~min}$. With this method, two-dimensional growth of $\mathrm{GaN}$ was achieved at a very early stage of growth as indicated by in-situ RHEED study. The growth temperatures were varied from $550{ }^{\circ} \mathrm{C}$ to $700{ }^{\circ} \mathrm{C}$.

A Filmetrics F20 thin film measurement system was used to determine film thickness. The typical GaN layer thickness for this study was less than $300 \mathrm{~nm}$. An AFM made by Park Scientific Instrument (Autoprobe CP), operated in the contact mode, was used to study the asgrown GaN layer surface morphologies. RS measurements were performed using a triple monochromator T64000

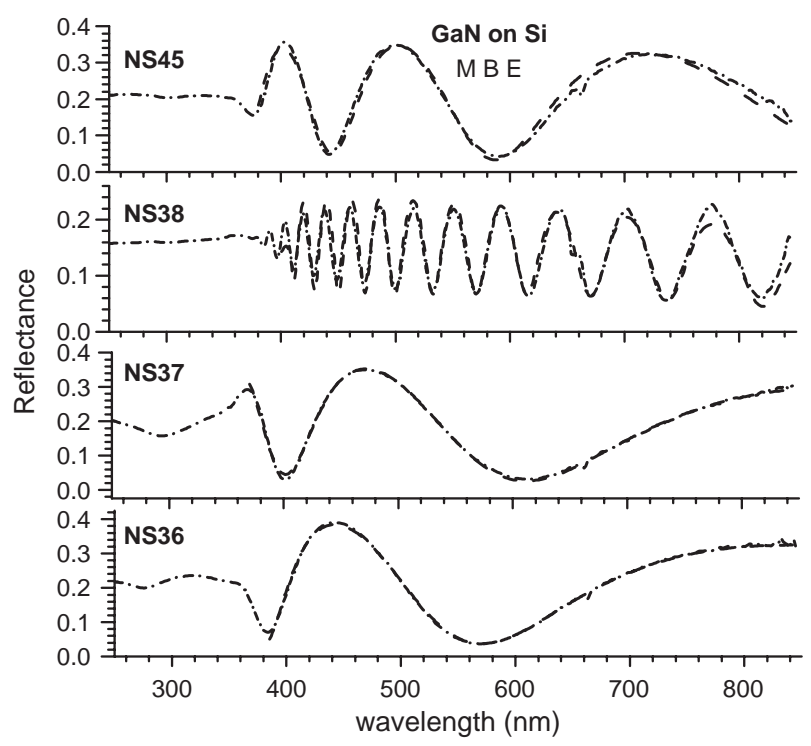

Fig. 3. The optical reflectance spectra for four MBE GaN/Si, measured in $250-850 \mathrm{~nm}$ with simulation done in $400-850 \mathrm{~nm}$. 
Whole Image

Area Ra: $\quad 0.1030 \mathrm{~nm}$ AreaRMS: $0.1280 \mathrm{~nm}$ Avg. Height: $0.5939 \mathrm{~nm}$ Max. Range: $1.1584 \mathrm{~nm}$

Partial Image

AreaRa: $\quad 0.0815 \mathrm{~nm}$ AreaRMS: $0.0991 \mathrm{~nm}$ Avg. Height: $0.5986 \mathrm{~nm}$ Height. Max. $0.6318 \mathrm{~nm}$

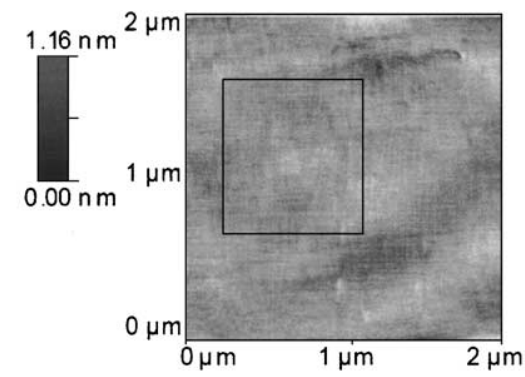

Fig. 4. AFM surface scan and roughness analysis of GaN/Si (111) grown with PSIMBE.

high resolution micro-Raman system excited at $514.5 \mathrm{~nm}$ from an Ar-ion laser. The spectral resolution was better than $1 \mathrm{~cm}^{-1}$. UV-PL was performed using a Renishaw UV micro-PL-Raman system, excited by $325 \mathrm{~nm}$ from a $\mathrm{HeCd}$ laser. All measurements were performed at room temperature. The X-ray diffraction spectra were measured by a Philips MRT high resolution system equipped with 5 crystals. The 2-thelta angle scan resolution is better than $0.0005^{\circ}$, i.e. 2 -arcseconds.

\section{Results and discussion}

Preliminary studies showed that an AIN buffer layer is still needed for single crystal GaN/Si growth. It was found that the smoothest initial growth of $\mathrm{GaN}$ can be obtained with the AlN buffer layer less than $10 \mathrm{~nm}$, as determined by in-situ RHEED and AFM studies. The RHEED pattern of the AlN layer with thickness of $5 \mathrm{~nm}$ is shown in Fig. 1(a). The surface roughness increased quickly when the AlN buffer thickness was greater than $10 \mathrm{~nm}$. A typical RHEED pattern of GaN grown with pulsed-source injection MBE is shown in Fig. 1(b). This stripe pattern typically appeared after 2 or 3 periods of source injections indicating that the 2-D growth starts at a very early stage of growth.

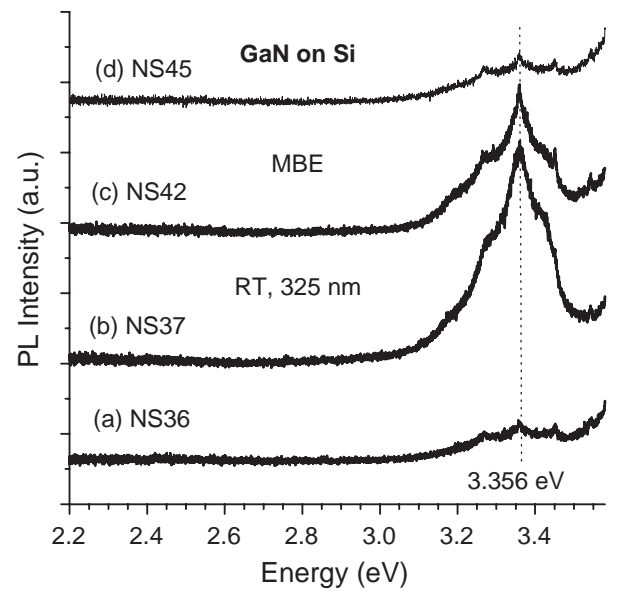

Fig. 5. RT PL spectra for four GaN/Si.

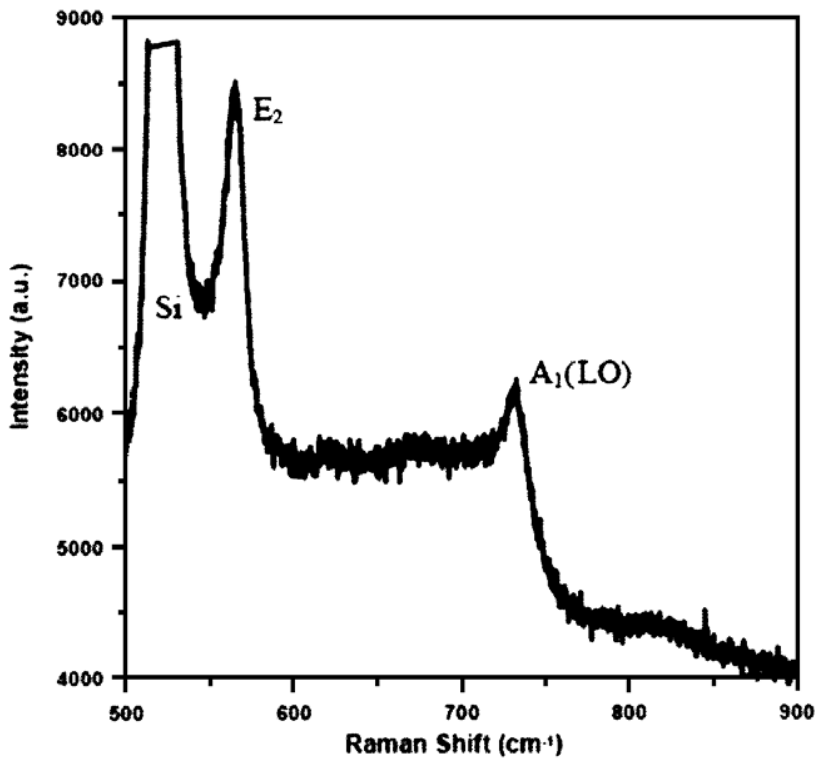

Fig. 6. Raman spectra of three MBE GaN/Si,NS42 (579 nm), NS38 (1522 $\mathrm{nm})$ and NS36 (182 $\mathrm{nm})$.

In Fig. 2, it is a typical high resolution XRD pattern for a PSIMBE grown $\mathrm{GaN} / \mathrm{Si}(111)$ film. Strong peaks at $34.6^{\circ}$ and $73^{\circ}$ are due to wurtzite $\mathrm{GaN}(0002)$ and (0004) diffractions, respectively. This indicates the GaN layer in the growth direction with the preferred orientation along the $c$-axis of wurtzite crystalline structure [20]. The strong high order $\mathrm{GaN}$ (0004) diffraction peak indicates that a high quality, single crystal $\mathrm{GaN}$ film was obtained on $\mathrm{Si}$.

Fig. 3 shows the optical reflectance (OR) spectra in 250-850 nm for four GaN samples grown on Si substrate by MBE. The simulation on the OR spectra in $400-850$

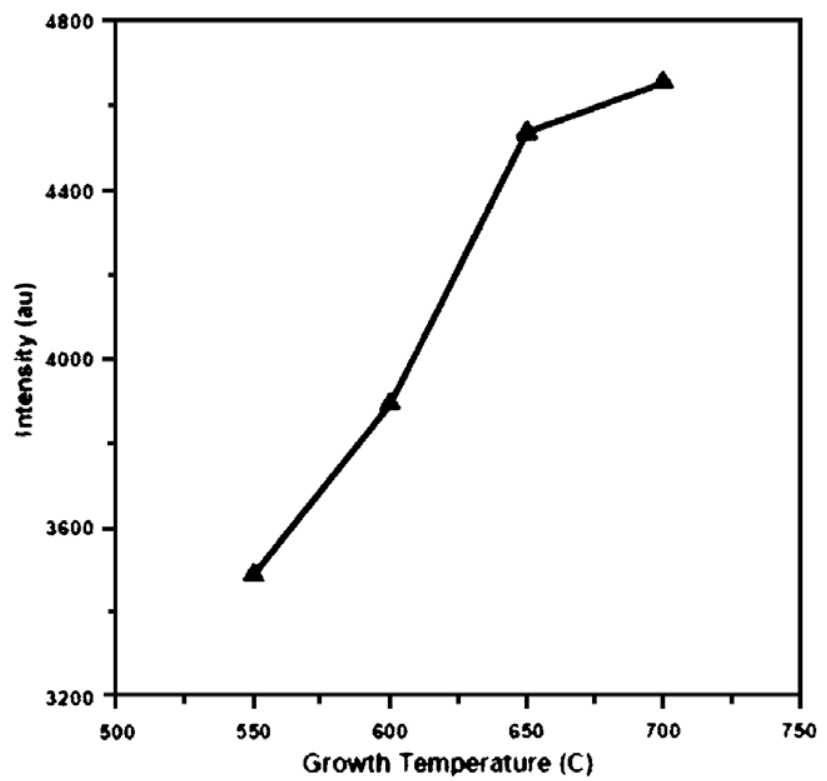

Fig. 7. $E_{2}$ band peak intensity of $\mathrm{GaN} / \mathrm{Si}(111)$ thin films vs. growth temperatures. 
Table 1

MBE growth and sample information

\begin{tabular}{|c|c|c|c|c|c|}
\hline Sample no. & NS36 & NS37 & NS38 & $\begin{array}{l}\text { NS42 } \\
\text { (Si 100) }\end{array}$ & NS45 \\
\hline $\begin{array}{l}\text { Growth temp. } \\
\left({ }^{\circ} \mathrm{C}\right)\end{array}$ & 650 & 700 & 700 & 700 & 650 \\
\hline $\begin{array}{l}\text { Growth time } \\
\text { (min) }\end{array}$ & 120 & 120 & 600 & 120 & 120 \\
\hline Thickness (nm) & 182 & 204 & 1522 & 579 & 315 \\
\hline Ga flux (Torr) & $2.1 \times 10^{-7}$ & $2.0 \times 10^{-7}$ & $2.1 \times 10^{-7}$ & $1.9 \times 10^{-7}$ & \\
\hline $\begin{array}{l}\mathrm{N} \text { flow rate } \\
(\mathrm{sccm})\end{array}$ & 0.6 & 0.6 & 0.6 & 0.6 & 0.6 \\
\hline $\begin{array}{l}\text { Ga pulse width } \\
\text { (s) }\end{array}$ & 120 & 120 & 80 & 60 & 90 \\
\hline $\mathrm{N}$ pulse with (s) & 120 & 120 & 40 & 60 & 30 \\
\hline
\end{tabular}

$\mathrm{nm}$ gives the film thickness. The experimental $\mathrm{GaN}$ layer thickness was varying from $\sim 180 \mathrm{~nm}$ up to $\sim 1500 \mathrm{~nm}$.

The GaN film surface morphology was studied by atomic force microscopy [3,16-19]. Fig. 4 shows an AFM image for a piece of $\mathrm{GaN}$ film on $\mathrm{Si}$, indicating that GaN layer grown using the PSIMBE process has a very smooth surface with an area RMS of about $0.13 \mathrm{~nm}$ only. Room temperature (RT) PL spectra, as shown in Fig. 5, of these $\mathrm{GaN}$ thin layers shows a $3.356 \mathrm{eV}$ as $\mathrm{GaN}$ edge band. However, the peak intensity was low since these films are very thin. It is red-shifted in comparison with the PL value from MOCVD-grown $\mathrm{GaN} / \mathrm{Si}$, and the peak intensity was low since these films are very thin [15]. Fig. 6 is a typical RS spectrum of $\mathrm{GaN} / \mathrm{Si}$ film grown by PSIMBE. A strong band centered at $520 \mathrm{~cm}^{-1}$ is from the $\mathrm{Si}$ substrate. Two Raman bands, phonon modes of high $E_{2}$ at $567 \mathrm{~cm}^{-1}$ and $A_{1}(\mathrm{LO})$ at $736 \mathrm{~cm}^{-1}$ due to the wurtzite (w-) GaN crystal, can be clearly seen. The wGaN characteristic $E_{2}$ and $A_{1}(L O)$ modes are shown clearly for the thickest film NS38 $(1500 \mathrm{~nm})$ and the 2nd thicker film NS42 $(579 \mathrm{~nm})$. These two modes appeared as shoulders from other three films thinner than $315 \mathrm{~nm}$. Two Raman bands, phonon modes of high $\mathrm{E}_{2}$ at $567 \mathrm{~cm}^{-1}$ and $A_{1}(\mathrm{LO})$ at $736 \mathrm{~cm}^{-1}$, due to the wurtzite $\mathrm{GaN}$ crystal, can be clearly seen in Fig. 6 [21]. A plot of $E_{2}$ band peak intensity vs. growth temperatures indicates that the proper growth temperature is in the range of 650 to $700{ }^{\circ} \mathrm{C}$, as shown in Fig. 7. Room temperature PL spectrum of these GaN thin layers also shows a $3.4 \mathrm{eV}$ $\mathrm{GaN}$ edge band. However, the peak intensity was low since these films are very thin (Table 1).

\section{Conclusion}

A pulse source injection MBE technique was successfully developed to grow extremely smooth thin GaN films. This pulsed-source growth process is different from the atomic layer epitaxy (ALE) process which provides one atomic layer of material growth for each complete source injection period. In the PSIMBE process, multi- layers of $\mathrm{GaN}$ is grown for each source injection period. Calculations based on the growth rate, indicated that the pulsed source injection MBE process grew eight GaN lattice constants of material for a 3 min source injection period. The PSIMBE process has a faster growth rate than the ALE process. It is believed that this pulsed source injection process provides a sufficiently long relaxation time to allow high mobility Ga atoms to move to the nuclear sites at island boundaries and thereby form layer by layer 2-dimensional growth. Therefore, it can be treated as a migration enhanced growth process. However, detailed growth studies need to be continued to completely understand the growth mechanisms for further process optimization.

\section{Acknowledgements}

The work at National Taiwan University was supported by funds from National Science Council of Republic of China, NSC 93-2218-E-002-011 and 932215-E-002-035.

\section{References}

[1] S. Nakamura, S. Pearton, G. Fasol, The Blue Laser Diode-The Complete Story, Springer, Berlin, 2000.

[2] M.O. Manasreh, I T. Ferguson (Eds.), III-V Nitride semiconductors: growth, vol. 19, in: M. O. Manasreh (Ed.), Optoelectronic Properties of Semiconductors and Superlattices (New York, Taylor \& Francis, 2003).

[3] M.-H. Kim, Y.-G. Do, H.C. Kang, D.Y. Noh, S.-J. Park, Appl. Phys. Lett. 79 (2001) 2713.

[4] X. Zhang, S.J. Chua, P. Li, K.B. Chong, Z.C. Feng, Appl. Phys. Lett. 74 (1999) 1984.

[5] X. Zhang, Y.T. Hou, Z.C. Feng, J. Chen, J. Appl. Phys. 88 (2001) 6165.

[6] A. Dadgar, M. Poschenrieder, A. Reiher, J. Blasing, J. Christen, A. Krtschil, T. Finger, T. Hempel, A. Diez, A. Krost, Appl. Phys. Lett. 82 (2003) 28.

[7] Yuan Lu, Guangwei Cong, Xianglin Liu, Da-Cheng Lu, Qinsheng Zhu, Xiaohui Wang, Jiejun Wu, Zhanguo Wang, J. Appl. Phys. 96 (2004) 4982.

[8] Kang Jea Lee, Eun Ho Shin, Kee Young Lim, Appl. Phys. Lett. 85 (2004) 1502.

[9] L.S. Wang, K.Y. Zang, S. Tripathy, S.J. Chua, Appl. Phys. Lett. 85 (2004) 5881.

[10] Yuan Lu, Xianglin Liu, Xiaohui Wang, Da-Cheng Lu, Dabing Li, Xiuxun Han, Guangwei Cong, Zhanguo Wang, J. Cryst. Growth 263 (2004) 4.

[11] E. Calleja, M.A. Sànchez-García, D. Basak, F.J. Sànchez, F. Calle, P. Youinou, E. Muñoz, J.J. Serrano, J.M. Blanco, C. Villar, T. Laine, J. Oila, K. Saarinen, P. Hautojärvi, C.H. Molloy, D.J. Somerford, Phys. Rev., B 58 (1998) 1550.

[12] J.W. Yang, A. Lunev, G. Simin, A. Chitnis, M. Shatalov, M. Asif Khan, J.E. Van Nostrand, R. Gaska, Appl. Phys. Lett. 76 (2000) 273.

[13] E. Calleja, M.A. Sànchez-García, F. Calle, F.B. Naranjo, E. Muñoz, U. Jahn, K. Ploog, J. Sànchez, J.M. Calleja, K. Saarinen, P. Hautojärvi, Mater. Sci. Eng., B, Solid-State Mater. Adv. Technol. $82(2001) 2$. 
[14] J.Y. Duboz, J.L. Reverchon, D. Adam, B. Damilano, N. Grandjean, F. Semond, J. Massies, J. Appl. Phys. 92 (2002) 5602.

[15] J.W. Yu, H.C. Lin, Z.C. Feng, L.S. Wang, S.J. Chua, Surf. Coat. Technol. (in this issue)

[16] K.J. Lee, E.H. Shin, K.Y. Lim, Appl. Phys. Lett. 85 (2004) 1502.

[17] C.A. Tran, A. Osinski, R.F. Karlicek Jr., I. Berisher, Appl. Phys. Lett. 75 (1999) 1494.
[18] S. Zamir, B. Meyler, J. Salzman, J. Cryst. Growth 230 (2001) 341.

[19] J. Wan, R. Venugopal, M.R. Melloch, H.M. Liaw, W.J. Rummel, Appl. Phys. Lett. 79 (2001) 1459.

[20] Z.C. Feng, X. Zhang, S.J. Chua, T.R. Yang, J.C. Deng, G. Xu, Thin Solid Films 409 (2002) 15.

[21] Z.C. Feng, Opt. Eng. 41 (2002) 2022. 